\title{
Profile of betrixaban and its potential in the prevention and treatment of venous thromboembolism
}

This article was published in the following Dove Press journal:

Vascular Health and Risk Management

26 June 2015

Number of times this article has been viewed

\author{
Noel C Chan ${ }^{1,2}$ \\ Vinai Bhagirath ${ }^{1,3}$ \\ John W Eikelboom 1,3,4 \\ 'Population Health Research Institute, \\ Hamilton, ON, Canada; ${ }^{2}$ Department \\ of Haematology, Monash Medical \\ Center, Clayton, VIC, Australia; \\ ${ }^{3}$ Thrombosis and Atherosclerosis \\ Research Institute, ${ }^{4}$ Department \\ of Medicine, McMaster University, \\ Hamilton, ON, Canada
}

\begin{abstract}
Venous thromboembolism (VTE), which includes deep vein thrombosis and pulmonary embolism, is a common and potentially preventable cause of morbidity and mortality. Unfractionated heparin, low-molecular-weight heparin, and warfarin have been the cornerstone of VTE prevention and treatment but are being replaced by recently approved non-vitamin $\mathrm{K}$ antagonist oral anticoagulants (NOACs): dabigatran, rivaroxaban, apixaban, and edoxaban. The NOACs are at least as effective and as safe as heparins and warfarin for VTE prevention and treatment and are more convenient because they have a low propensity for food and drug interactions and are given in fixed doses without routine coagulation monitoring. The remaining limitations of currently available NOACs include their dependence on renal and hepatic function for clearance, and the lack of an approved antidote. Betrixaban is a new NOAC with distinct pharmacological characteristics: minimal renal clearance, minimal hepatic metabolism, and long half-life. It has undergone successful Phase II studies in orthopedic thromboprophylaxis, and in stroke prevention in atrial fibrillation. Currently, it is being evaluated in a Phase III trial of extended thromboprophylaxis in medical patients (APEX study). In this article, we describe the development of betrixaban, review its pharmacological profile, discuss the results of clinical trials, and examine its potential for VTE prevention and treatment.
\end{abstract}

Keywords: betrixaban, factor Xa inhibitors, anticoagulant, pharmacology, venous thromboembolism

\section{Introduction}

Venous thromboembolism (VTE), manifesting as either a deep vein thrombosis (DVT) or a pulmonary embolism (PE), is an important cause of morbidity and mortality worldwide and a leading cause of preventable death in hospitalized patients. ${ }^{1,2}$ The heparins (unfractionated heparin low-molecular-weight heparin [LMWH]) and warfarin have been the cornerstone of VTE prevention and treatment for more than half a century. ${ }^{3}$ Although effective, they have well-known limitations. ${ }^{4}$ In an attempt to overcome those limitations, orally administered direct thrombin inhibitors and direct factor Xa (FXa) inhibitors were developed and were evaluated in large Phase III trials for VTE treatment and prevention. ${ }^{5}$ Four non-vitamin $\mathrm{K}$ antagonist oral anticoagulants (NOACs), namely, dabigatran, rivaroxaban, apixaban, and more recently, edoxaban, have been shown to be at least as effective and safe as warfarin for VTE treatment and are now approved for this indication. ${ }^{6-11}$ They have also been approved for VTE prevention in major orthopedic surgery. Similar to the heparins, NOACs have rapid onset of action, and the peak plasma level is reached within 3 hours of administration. In contrast to the heparins, they have the advantage of oral administration, and in
Correspondence: Noel C Chan RI3-I3B, Population Health Research Institute, 237 Barton Street East Hamilton, ON L8L 2X2, Canada Tel +l 9055274322 ext 40520

Fax +l 9052973785

Email noel.chan@phri.ca 
contrast to warfarin, they have predictable pharmacology, less variability in anticoagulant effect, and less drug/food interactions, leading to the convenience of fixed dosing without the need for monitoring.

With the availability of four NOACs competing for similar indications, any additional NOAC would ideally need to have unique pharmacological properties that overcome existing limitations or be developed for an indication that fills an unmet need. Because of their reliance on renal clearance and hepatic metabolism, the currently approved NOACs have the potential to accumulate in patients with severe renal or liver impairment, and caution is required with rivaroxaban, apixaban, and edoxaban when administered concomitantly with potent cytochrome 450 (CYP450) inducers or inhibitors. Furthermore, due to their short half-lives resulting in relatively rapid offset of action, missing doses may predispose patients to thrombosis. Betrixaban, a new direct FXa inhibitor, stands out because it has the lowest renal clearance ( $<7 \%$ of administered dose), minimal hepatic metabolism $(<1 \%)$, and a long half-life (terminal half-life $=37$ hours). Betrixaban has been tested in Phase II studies for VTE prevention in total knee replacement (EXPERT trial) and for stroke prevention in atrial fibrillation (EXPLORE-Xa trial), ${ }^{12,13}$ and it is currently being evaluated in a Phase III trial (APEX) for extended thromboprophylaxis in medical patients at high risk of VTE, an indication for which there is no approved anticoagulant. ${ }^{14}$ If this clinical development program succeeds, betrixaban could be the fifth NOAC to be introduced for the management of VTE. In this article, we describe the development of betrixaban, review its pharmacological profile, discuss the results of clinical trials, and examine its potential for VTE prevention and treatment.

\section{Chemical development}

Betrixaban is a direct FXa inhibitor developed by Portola Pharmaceuticals Inc. (San Francisco, CA, USA). It is derived from 1,N-(5-chloropyridin-2-yl)-2-(4-( $N$, $N$-dimethylcarbamimidoyl)-benzamido)benzamide, an anthranilamide-based compound with potent FXa inhibitory activity (IC50 $3 \mathrm{nM}$, Ki $1.4 \mathrm{nM}) .{ }^{15}$ Through an iterative process, several analogs of the parent compound were synthesized by substitution at three phenyl rings, and the potential candidate compounds were selected on the basis of FXa inhibitory activity by performing structure-activity relationship studies. Many of the selected compounds, however, also showed high affinity toward hERG channel - a cardiac potassium ion channel that mediates cardiac repolarization. Inhibition of hERG channels is associated with delayed cardiac repolarization, QT prolongation, and the risk of life threatening arrhythmias, raising safety concerns. Subsequent structure-activity relationship studies led to the selection of the methoxy-substituted compound 11, as the candidate drug for further development because it retained potent selective FXa inhibition (IC50 $=1.5 \mathrm{nM}$, $\mathrm{Ki}=0.117)$, least hERG channel binding $(\mathrm{IC50}=8.9 \mu \mathrm{M})$, and an acceptable pharmacokinetic/pharmacodynamic profile in animal models. ${ }^{15}$

\section{Pharmacological profile of betrixaban \\ Preclinical studies}

Several preclinical studies were performed to establish the mechanism of action of betrixaban and to define an effective and safe antithrombotic dose. As detailed later, these studies confirmed that betrixaban exerts its antithrombotic effect by inhibiting free and prothrombinase-bound FXa in a concentration-dependent manner. ${ }^{12,15-17}$ They also suggest that betrixaban in concentrations ranging from $5 \mathrm{ng} / \mathrm{mL}$ to $25 \mathrm{ng} / \mathrm{mL}$ might produce clinically effective antithrombotic effect in humans. ${ }^{13}$

\section{Effects on in vitro assays}

In a whole blood prothrombinase inhibition assay, betrixaban showed dose-dependent inhibition of platelet-mediated prothrombinase activity consistent with its mechanism of action. ${ }^{16}$ For equivalent anti-FXa activities, betrixaban was more potent at inhibiting TAT complex and F1+2 generation when compared to fondaparinux. ${ }^{17}$ In a tissue factor-induced thrombin generation assay, betrixaban in concentrations ranging from $5 \mathrm{ng} / \mathrm{mL}$ to $25 \mathrm{ng} / \mathrm{mL}$ inhibited thrombin generation to a comparable degree as trough, and the peak levels were achieved by $2.5 \mathrm{mg}$ fondaparinux. ${ }^{17}$ Preclinical toxicology studies using patch clamp hERG assays showed that betrixaban was not a potent hERG channel inhibitor $(\mathrm{IC} 50=8.9 \mu \mathrm{M}) .{ }^{15}$ They also suggest that the doses of betrixaban that will be clinically used would provide a 30-fold margin of safety (ratio of hERG IC50 to expected peak plasma concentration of betrixaban) against significant hERG channel inhibition. ${ }^{15}$

\section{Effects on venous and arterial thrombosis in animal models}

The antithrombotic efficacy of betrixaban was evaluated in three animal models: i) rabbit vena cava model, ii) rodent ferric chloride carotid artery model, and iii) baboon AV 
shunt model. ${ }^{17}$ In the rabbit abdominal vena cava model of clot accretion on cotton threads, betrixaban in doses of $3 \mathrm{mg} /$ $\mathrm{kg}$ showed nearly comparable inhibition of thrombus mass to enoxaparin $1.6 \mathrm{mg} / \mathrm{kg}$ (76\% vs 96\% inhibition). Betrixaban in doses of $19.1 \mathrm{mg} / \mathrm{kg}$ was at least as effective at maintaining patency as enoxaparin $7.6 \mathrm{mg} / \mathrm{kg}$ and clopidogrel $3 \mathrm{mg} / \mathrm{kg} / \mathrm{d}$ ( $90 \%$ vs $70 \%$ vs $80 \%$ patency, respectively) in the ferric chloride injury model of rodent carotid artery. Finally, betrixaban demonstrated the dose-dependent inhibition of 111-Indium (111-In)-labeled platelet deposition at both the venous and arterial side of the baboon AV shunt thrombosis model when used in doses ranging from $0.05 \mathrm{mg} / \mathrm{kg}$ to $0.49 \mathrm{mg} / \mathrm{kg}$. This dose range produced an average plasma concentration of $7-83 \mathrm{ng} / \mathrm{mL}$ and resulted in $30 \%-90 \%$ inhibition of platelet deposition at the venous side of the AV shunt.

\section{Effects on ex vivo coagulation testing of animal and human plasma}

To establish the usefulness of coagulation assays in predicting antithrombotic efficacy and in measuring the anticoagulant effect of betrixaban, several assays were tested in ex vivo samples. Clotting assays, including prothrombin time (PT), activated partial thromboplastin time (aPTT), and activated clotting time (ACT), were relatively insensitive to the anticoagulant effect of betrixaban and showed a differential species response. Doubling of PT was attained at $8.9 \mu \mathrm{M}, 1.6 \mu \mathrm{M}, 1.0 \mu \mathrm{M}$, and $0.4 \mu \mathrm{M}$ concentrations in rat, rabbit, baboon, and human plasma, respectively. Based on the available data, doubling of $\mathrm{PT}$ in human would require a concentration of $\sim 180 \mathrm{ng} / \mathrm{mL}$, which is well above the purported clinically effective antithrombotic concentration range of 5-25 ng/mL. Thus, at concentrations that produced an antithrombotic effect, betrixaban is not expected to cause significant prolongation of PT in human. ${ }^{16,17}$ Detailed data for aPTT and ACT have not been published, but these assays are likely to be as insensitive to the anticoagulant effect of betrixaban as the PT.

The prothrombinase inhibition and the anti-FXa assays are more sensitive to the effect of betrixaban than clotting assays and may be useful in measuring its antithrombotic effect. Of the two assays, suppression of thrombin generation as measured by the prothrombinase inhibition assay correlated best with the antithrombotic activity of the drug in the baboon AV shunt model (correlation coefficient, $\left.R^{2}=0.99\right) \cdot{ }^{13,14,16-19}$

Because the routinely available clotting assays, PT or aPTT, are relatively insensitive to levels achieved therapeutically, measurement and quantitation of betrixaban level in clinical practice will require the use of other tests such as the anti-FXa assay, as exemplified by current practice with other established FXa inhibitors.

\section{Pharmacokinetics of betrixaban}

Similar to other approved direct FXa inhibitors, betrixaban at a dose of $80 \mathrm{mg}$ showed rapid absorption and peak plasma concentration within 3-4 hours of oral administration in healthy human volunteers. ${ }^{13,14,17-19}$ The oral bioavailability is $34 \%$ and is affected by fatty food, which reduces the peak concentration and area under the curve by $50 \%$. About $60 \%$ of the drug is protein bound in plasma.

Betrixaban is primarily excreted in the gut $(82 \%-89 \%)$ through the hepatobiliary route, likely via permeability glycoprotein (P-gp) efflux pump as mostly unchanged drug. Betrixaban is minimally metabolized $(<1 \%)$ by CYP450 enzymes and does not induce or inhibit CYP450. ${ }^{20}$ It has the least renal clearance of all approved NOACs so far (5\%-7\% of orally administered dose). ${ }^{13,14}$

The terminal half-life (time for concentration to be reduced by $50 \%$ ) is 37 hours, and the pharmacodynamic half-life (time for efficacy to be reduced by 50\%) is $\sim 20$ hours. As a consequence, betrixaban exhibits a low peak-to-trough drug concentration ratio. ${ }^{20}$

\section{Comparative pharmacology and clinical implications}

In comparison to other approved NOACs (Table 1), betrixaban stands out on account of four characteristics: the least renal clearance, the least hepatic metabolism, the most gastrointestinal (GI) clearance, and the longest half-life. Thus, the dependence on renal clearance of approved NOACs varies from $80 \%$ with dabigatran to $66 \%, 35 \%$, and $25 \%$ with rivaroxaban, edoxaban, and apixaban, respectively. ${ }^{21-24}$ Since only $5 \%-7 \%$ of orally administered betrixaban is renally cleared, its unique pharmacological profile may allow broader use to include patients with renal impairment ( $\mathrm{CrCl}<30 \mathrm{~mL} / \mathrm{min}$ ), a population excluded from previous NOAC trials and with limited anticoagulant option. ${ }^{13,14}$ With minimal hepatic metabolism $(<1 \%)$, drug-to-drug interaction occurring as a result of CYP450 induction or inhibition is unlikely, and the accumulation in patients with liver impairment would be less likely. However, based on its reliance on the hepatobiliary system as a main mechanism of clearance, accumulation may be expected to occur in obstructive jaundice. Because betrixaban is a substrate for P-gp, drug-to-drug interaction is expected 
Table I Comparative pharmacology of non-vitamin K antagonist oral anticoagulants

\begin{tabular}{|c|c|c|c|c|c|}
\hline & Dabigatran & Rivaroxaban & Apixaban & Edoxaban & Betrixaban \\
\hline Target & Ila & $\mathrm{Xa}$ & $\mathrm{Xa}$ & $\mathrm{Xa}$ & $\mathrm{Xa}$ \\
\hline Bioavailability & $6 \%-7 \%$ & $66 \%$ & $50 \%$ & $62 \%$ & $34 \%$ \\
\hline Protein binding & $35 \%$ & $92 \%-95 \%$ & $87 \%$ & $40 \%-59 \%$ & $60 \%$ \\
\hline$T_{\max }(\mathrm{h})$ & 2 & $2-4$ & $1-3$ & $\mathrm{I}-2$ & $3-4$ \\
\hline Metabolism via CYP450 & $<2 \%$ & $57 \%$ & $<32 \%$ & $<25 \%$ & $<1 \%$ \\
\hline Renal excretion & $>80 \%$ & $66 \%$ & $25 \%$ & $35 \%$ & $6 \%-13 \%$ \\
\hline Fecal excretion & $82 \%-88 \%$ & $26.4 \%$ & $46.7 \%-56 \%$ & $62.2 \%$ & $82 \%-89 \%$ \\
\hline$T_{1 / 2}(\mathrm{~h})$ & $12-14$ & $9-13$ & $8-15$ & $9-11$ & $37\left(\mathrm{PD} T_{1 / 2}=20 \mathrm{~h}\right)$ \\
\hline
\end{tabular}

Abbreviations: $T_{\max }$, time to reach peak concentration in plasma after oral dose; h, hours; CYP450, cytochrome 450; $T_{1 / 2}$, terminal half-life of drug; PD $T_{1 / 2}$, pharmacodynamic half-life.

to occur with potent P-gp inhibitors. Thus, concomitant administration of strong P-gp inhibitors (ketoconazole, amiodarone, and diltiazem) increases betrixaban concentration around twofold. ${ }^{14}$ Additionally, because $>82 \%$ unchanged drug is cleared via the GI tract, GI side effects may be more pronounced. ${ }^{12}$ Although the long half-life and a low peak-to-trough drug concentration ratio should minimize anticoagulant variability thereby ensuring a consistent anticoagulant effect over a 24 hours period and minimizing the effect of a missed dose, it could be problematic in patients who bleed or who require urgent surgery in the absence of an antidote.

\section{Early clinical studies: dose finding, clinical efficacy, and safety}

Doses for Phase II studies were selected to achieve a target concentration range of 5-25 $\mathrm{ng} / \mathrm{mL}$ based on the results of a comparative in vitro study that showed a similar degree of inhibition of thrombin generation to fondaparinux $2.5 \mathrm{mg}$ (an established VTE prevention dose) and the results of concentration-response relationship from the baboon AV shunt model. ${ }^{13,16,17}$ Selection of the oral dose range (30-80 mg) was subsequently informed by pharmacokinetic data obtained from Phase I studies in healthy humans, which suggested that this dose range would produce concentrations spanning the target concentration range. ${ }^{13}$ Betrixaban subsequently underwent Phase II studies in orthopedic thromboprophylaxis (EXPERT trial), and in atrial fibrillation (EXPLORE-Xa trial), respectively. ${ }^{12,13}$ Despite the long half-life of betrixaban, twice daily doses (15 mg bid and $40 \mathrm{mg}$ bid) were compared to enoxaparin $30 \mathrm{mg}$ bid in the EXPERT trial. ${ }^{13}$ As discussed by the investigators, a bid dosing regimen was selected to mimic a possible future controlled-release formulation and to examine its effect on reducing diurnal variability in the anticoagulant effect of betrixaban. ${ }^{13}$ In EXPLORE-Xa, daily doses of $40 \mathrm{mg}, 60 \mathrm{mg}$, and $80 \mathrm{mg}$ were compared to warfarin. $^{12}$

\section{Phase II EXPERT trial: VTE prevention in total knee replacement}

The EXPERT trial $(n=214)$ was an open-label blindedendpoint Phase II randomized controlled trial comparing the efficacy and safety of two betrixaban doses, $15 \mathrm{mg}$ bid and $40 \mathrm{mg}$ bid administered 6-8 hours postoperatively, with enoxaparin $30 \mathrm{mg} \mathrm{sc}$ bid, administered 12-24 hours postoperatively, in patients undergoing total knee replacement (Table 2). ${ }^{13}$ The primary efficacy outcome was the occurrence of objectively diagnosed VTE, a composite of symptomatic VTE and venographic DVT. The safety outcome was the occurrence of clinically relevant bleeding, a composite of major and clinically significant nonmajor bleeding. The primary efficacy outcome occurred in 20\% (95\% confidence interval [CI]: 11.4\%-31.3\%), 15\% (95\% CI: 7.6\%-26.5\%), and 10\% (95\% CI: $2.8 \%-23.7 \%$ ) of patients receiving betrixaban $15 \mathrm{mg}$ bid, $40 \mathrm{mg}$ bid, and enoxaparin $30 \mathrm{mg}$ bid, respectively (Figure 1). Although betrixaban was associated with higher point estimates for thrombosis than enoxaparin, the event rates were not statistically different among the three arms. The corresponding clinically relevant bleeding rates were 0\% (95\% CI: $0 \%-4.2 \%$ ), 2.4\% (95\% CI: 0.3\%-8.3\%), and 7\% (95\% CI: 1.5\%-19.1\%), respectively (Figure 1). Because the clinical efficacy outcome data were not adequately informative for dose finding, additional comparative substudies using FXa inhibition and suppression of thrombin generation as surrogate outcomes were performed. In these studies, betrixaban $40 \mathrm{mg}$ bid showed similar anti-FXa activity as enoxaparin $30 \mathrm{mg}$ bid, but greater suppression of thrombin generation than the latter. The $15 \mathrm{mg}$ bid dose showed lower FXa inhibition than enoxaparin but similar decrease in thrombin generation. It is unknown whether 
Table 2 Design of Phase II and Phase III clinical trials of betrixaban

\begin{tabular}{|c|c|c|c|c|c|c|}
\hline $\begin{array}{l}\text { Study } \\
\text { (ref) }\end{array}$ & Indication & $\begin{array}{l}\text { Sample } \\
\text { size }\end{array}$ & $\begin{array}{l}\text { Intervention } \\
\text { arms }\end{array}$ & Control arms & Design & Clinical outcomes \\
\hline $\begin{array}{l}\text { Phase II } \\
\left(\text { EXPERT }^{13}\right)\end{array}$ & $\begin{array}{l}\text { VTE } \\
\text { prevention } \\
\text { total knee } \\
\text { replacement }\end{array}$ & 214 & $\begin{array}{l}\text { Betrixaban } 15 \mathrm{mg} \\
\text { bid and } 40 \mathrm{mg} \text { bid } \\
\text { orally, } 6 \mathrm{~h} \\
\text { postoperatively }\end{array}$ & $\begin{array}{l}\text { Enoxaparin } 30 \mathrm{mg} \\
\text { sc bid, I } 2-24 \mathrm{~h} \\
\text { postoperatively }\end{array}$ & $\begin{array}{l}\text { RCT, open } \\
\text { label but } \\
\text { blinded to } \\
\text { betrixaban } \\
\text { doses }\end{array}$ & $\begin{array}{l}\text { Primary efficacy: composite of proximal } \\
\text { and distal DVT identified by unilateral } \\
\text { mandatory venography of operated leg + } \\
\text { symptomatic proximal DVT or PE } \\
\text { between day } 10 \text { and day } 14 \\
\text { Primary safety: composite of major and } \\
\text { clinically significant nonmajor bleeding. }\end{array}$ \\
\hline $\begin{array}{l}\text { Phase II } \\
(\text { EXPLORE- } \\
\left.\mathrm{Xa}^{12}\right)\end{array}$ & $\begin{array}{l}\text { Stroke } \\
\text { prevention } \\
\text { in atrial } \\
\text { fibrillation }\end{array}$ & 561 & $\begin{array}{l}\text { Betrixaban } 40 \mathrm{mg} \text {, } \\
60 \mathrm{mg} \text {, and } \\
80 \mathrm{mg} \text { daily }\end{array}$ & $\begin{array}{l}\text { Warfarin } \\
\text { adjusted to INR } \\
2.0-3.0\end{array}$ & $\begin{array}{l}\text { RCT, open } \\
\text { label, but } \\
\text { blinded to } \\
\text { betrixaban } \\
\text { doses }\end{array}$ & $\begin{array}{l}\text { Primary safety: composite of major or } \\
\text { clinically relevant nonmajor bleeding. } \\
\text { Secondary efficacy: composite of death, } \\
\text { ischemic or nonischemic stroke, MI, or } \\
\text { systemic embolism. }\end{array}$ \\
\hline $\begin{array}{l}\text { Phase III } \\
\left(\text { APEX }^{14}\right)\end{array}$ & $\begin{array}{l}\text { Extended } \\
\text { prophylaxis } \\
\text { in high VTE } \\
\text { risk acutely } \\
\text { ill medical } \\
\text { patients }\end{array}$ & $\begin{array}{l}6,850 \\
\text { (planned) }\end{array}$ & $\begin{array}{l}\text { Betrixaban } 80 \mathrm{mg} \\
\text { daily for } 35-42 \text { days }\end{array}$ & $\begin{array}{l}\text { Enoxaparin } 40 \mathrm{mg} \\
\text { up to } 10 \pm 4 \text { days } \\
\text { followed } \\
\text { by placebo }\end{array}$ & $\begin{array}{l}\text { RCT, } \\
\text { blinded, } \\
\text { double } \\
\text { dummy }\end{array}$ & $\begin{array}{l}\text { Primary efficacy: composite of proximal } \\
\text { DVT-(detected by mandatory } \\
\text { ultrasound), symptomatic DVT-, nonfatal } \\
\text { PE- and VTE-related death between days } \\
35 \text { and } 42 \text {. } \\
\text { Primary safety: major bleeding through } \\
7 \text { days after discontinuation of all study } \\
\text { medications. }\end{array}$ \\
\hline
\end{tabular}

Abbreviations: VTE, venous thromboembolism; h, hours; INR, international normalized ratio; RCT, randomized controlled trial; DVT, deep vein thrombosis; PE, pulmonary embolism; Ml, myocardial infarction.

these favorable surrogate results will translate into clinical efficacy.

\section{EXPLORE-Xa trial: dose ranging study for stroke prevention in AF}

The safety and tolerability of three blinded doses of betrixaban - $40 \mathrm{mg}$ daily, $60 \mathrm{mg}$ daily, and $80 \mathrm{mg}$ daily - were compared to open-label warfarin in patients with nonvalvular

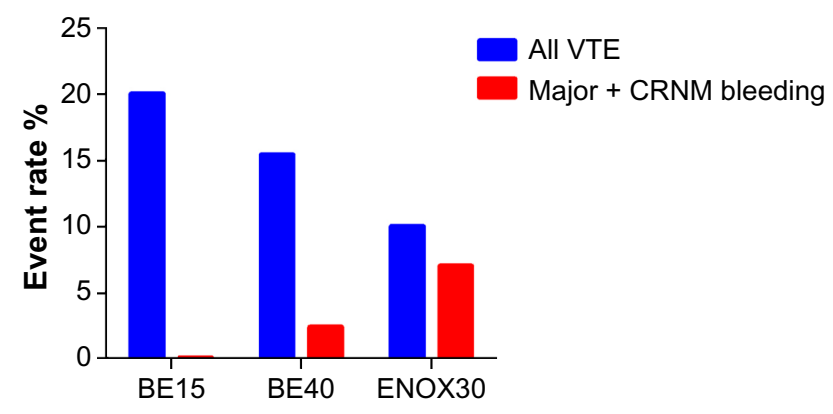

Figure I Clinical efficacy and safety of betrixaban in Phase II EXPERT trial. Notes: The EXPERT trial was a Phase II study comparing oral betrixaban $15 \mathrm{mg}$ bid (BEI5), and $40 \mathrm{mg}$ bid (BE40) with enoxaparin $30 \mathrm{mg}$ bid sc (ENOX30) in patients undergoing total knee replacement. All VTE (blue bars) occurred in $20 \%(95 \% \mathrm{Cl}$ : II.4\%-31.3\%), $15 \%$ (95\% Cl: $7.6 \%-26.5 \%$ ), and 10\% (95\% Cl: $2.8 \%-23.7 \%$ ) of patients receiving betrixaban $15 \mathrm{mg}$ bid, $40 \mathrm{mg}$ bid, and enoxaparin $30 \mathrm{mg}$ bid, respectively. The corresponding clinically relevant bleeding rates (red bars) were $0 \%(95 \% \mathrm{Cl}$ : $0 \%-4.2 \%$ ), $2.4 \%$ (95\% Cl: $0.3 \%-8.3 \%$ ), and $7.0 \%$ (95\% Cl: I.5\%-19.1\%), respectively. Abbreviations: VTE, venous thromboembolism; CRNM, clinically relevant nonmajor; $\mathrm{Cl}$, confidence interval. atrial fibrillation in the dose ranging EXPLORE-Xa trial $(n=561)$ (Table 2). ${ }^{12}$ Although the trial did not exclude patients with severe renal impairment, only a minority of patients $(8.1 \%)$ with glomerular filtration rate $($ GFR) $<40 \mathrm{~mL} / \mathrm{min}$ at baseline were enrolled. The primary safety outcome was the occurrence of clinically relevant bleeding, a composite of major and clinically relevant nonmajor bleeding. Secondary outcomes included all bleeding, death, ischemic and nonischemic stroke, myocardial infarction, and systemic embolism rates. All three doses of betrixaban ( $40 \mathrm{mg}, 60 \mathrm{mg}$, and $80 \mathrm{mg}$ ) showed lower point estimates for bleeding $(0.78 \%, 3.94 \%$, and $3.94 \%$, respectively) than warfarin (5.51\%). Only betrixaban $40 \mathrm{mg}$ daily showed statistically significant reduced bleeding than warfarin (hazard ratio $[\mathrm{HR}]=0.14, P=0.04$ ) (Figure 2). In total, two ischemic strokes (in $60 \mathrm{mg}$ and $80 \mathrm{mg}$ betrixaban arms) and two vascular deaths (in $40 \mathrm{mg}$ betrixaban and warfarin arms) occurred; these low event rates do not allow definitive conclusions to be made about relative efficacy. Surrogate outcomes of D-dimer and prothrombinase inhibition were also measured for population pharmacokinetic/ pharmacodynamic modeling substudies. All three doses of betrixaban suppressed $\mathrm{D}$-dimer and thrombin generation, but only the $80 \mathrm{mg}$ daily dose resulted in suppression of thrombin generation to a level similar to that achieved by warfarin at a therapeutic international normalized ratio. 


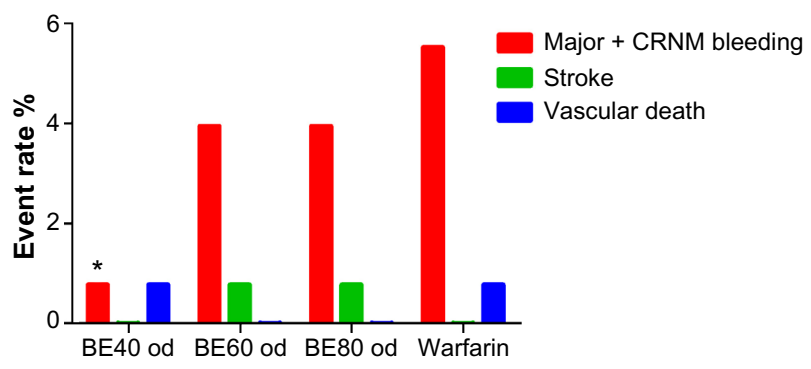

Figure 2 Clinical efficacy and safety of betrixaban in Phase II EXPLORE-Xa trial. Notes: The EXPLORE-Xa trial was a Phase Il study comparing oral betrixaban $40 \mathrm{mg}$ od (BE40), $60 \mathrm{mg}$ od (BE60), and $80 \mathrm{mg}$ od (BE80) with warfarin (adjusted to INR 2.0-3.0) in atrial fibrillation. Clinically relevant bleeding (major bleeding and clinically relevant nonmajor bleeding, red bars) occurred in 0.78\% (95\% Cl: $0.01 \%-4.76 \%), 3.94 \%$ ( $95 \% \mathrm{Cl}$ : I.45\%-9.12\%), 3.94\% (95\% Cl: $1.45 \%-9.12 \%)$, and $5.51 \%(95 \% \mathrm{Cl}: 2.50 \%-11.14 \%$ ) in BE40, BE60, BE80, and warfarin arms, respectively. Only betrixaban $40 \mathrm{mg}$ daily showed statistically significant lower rate of bleeding than warfarin $(H R=0.14, * P=0.04)$. Two ischemic strokes (one each in BE60 and BE80 arms, green bars) and two vascular deaths (one each in $\mathrm{BE}$ and warfarin arms, blue bars) occurred.

Abbreviations: CRNM, clinically relevant nonmajor; INR, international normalized ratio; $\mathrm{Cl}$, confidence interval; $\mathrm{HR}$, hazard ratio.

\section{Safety and tolerability in early studies Bleeding}

The pooled rate of clinically relevant bleeding was lower for betrixaban than control in both EXPERT (betrixaban vs enoxaparin: $1.2 \%$ vs $6.9 \%$ ) and EXPLORE-Xa (betrixaban vs warfarin: $2.9 \%$ vs $5.5 \%$ ). These results suggest that betrixaban in the dose range of 30-80 $\mathrm{mg}$ is at least as safe as enoxaparin for orthopedic thromboprophylaxis and as warfarin for stroke prevention in patients with AF.

\section{Gl and hepatic adverse events}

In EXPLORE-Xa, a significantly higher rate of diarrhea $(6.0 \%$ vs $0.8 \%)$ was observed in the betrixaban arms than the warfarin arm. Similarly, higher rates of nausea ( $11 \%$ vs $1.6 \%)$, dyspepsia ( $3.1 \%$ vs $0.8 \%$ ), and vomiting $(4.7 \%$ vs $0.8 \%)$ were reported with betrixaban $80 \mathrm{mg}$ daily than warfarin. ${ }^{12}$ However, most of the GI adverse events were mild and did not result in discontinuation of study drug.

A significant hepatotoxicity signal was not observed in Phases I and II studies. The rate of elevated alanine aminotransferase ( $>3$ times upper limit of normal) was not worse than control in EXPLORE-Xa (betrixaban vs warfarin: $1.8 \%$ vs $0.3 \%$ ) and EXPERT study (betrixaban vs enoxaparin: $2.0 \%$ vs $5.3 \%$, at discharge). ${ }^{12,13}$ The elevation in alanine aminotransferase was transient and did not show evidence of a dose-dependent response. Importantly, no case of elevated bilirubin was observed with betrixaban in the early clinical studies.

\section{QTc prolongation}

Betrixaban is derived from a class of compounds that has the potential to prolong the QTc interval through hERG channel inhibition and to cause cardiac arrhythmia. QTc prolongation was investigated in a single-dose crossover toxicology study in 96 healthy volunteers performed to meet ICH E14 regulatory requirements and in the EXPERT study. ${ }^{12,25}$ The first study showed that a single dose of betrixaban of either $80 \mathrm{mg}$ or $140 \mathrm{mg}$ was not associated with prolongation of QTc above the regulatory threshold (upper 95\% CI for the mean estimate of the difference of QTc from baseline $<10 \mathrm{~ms}$ ). Also, comparison of baseline and on treatment electrocardiograms (ECGs) in the EXPERT study did not show a significant effect of betrixaban on QTc interval.

\section{Clinical development in Phase III trial}

To ensure a competitive edge over the approved NOACs, the clinical development of betrixaban is targeting perceived unmet clinical needs, while taking advantage of its unique pharmacokinetic profile, namely minimal renal clearance. At the time of publication of this manuscript, one Phase III trial is ongoing in VTE prevention, and none in VTE treatment.

\section{Acute medically ill VTE prevention with extended duration betrixaban (APEX) study}

Although NOACs and LMWH are approved for extended VTE prophylaxis in major orthopedic surgery, and for high-risk surgery, there is currently no approved anticoagulant for extended VTE prophylaxis in medically ill patients. To address this need, the APEX study is evaluating the safety and efficacy of extended duration betrixaban (for up to 35 days) in acute medically ill patients at high risk of VTE. ${ }^{14}$ APEX is a double-blind, double-dummy, parallel-group, multicenter randomized controlled trial $(\mathrm{RCT})(\mathrm{n}=6,850)$ comparing betrixaban $80 \mathrm{mg}$ once daily for 35-42 days with enoxaparin $40 \mathrm{mg}$ once daily for 6-14 days. Patients with severe renal impairment $(\mathrm{CrCl}<30 \mathrm{~mL} / \mathrm{min})$, but not end stage renal failure $(\mathrm{CrCl}<15 \mathrm{~mL} / \mathrm{min}$ or receiving dialysis), are being included for the first time in a Phase III NOAC trial and will receive $50 \%$ reduced dose of study medications based on the findings from pharmacometric modeling. ${ }^{14}$ The primary efficacy outcome is a composite of asymptomatic proximal DVT (as detected by mandatory ultrasound), symptomatic DVT, nonfatal PE, and VTE-related 
death between days 35 and 42 . The primary safety outcome is the occurrence of major bleeding through 7 days after discontinuation of study medications. Betrixaban $80 \mathrm{mg}$ daily was selected based on the pharmacometric modeling of anti-Xa activity and suppression of thrombin generation in the Phase II studies. Study completion is expected by September 2015. ${ }^{14,26}$

Extended thromboprophylaxis with anticoagulant in medical patients is a challenge because of the heterogeneity of this population leading to wide variability in VTE risk and because of the risk of bleeding. Previous RCTs evaluating extended thromboprophylaxis in relatively unselected medical patients have consistently failed to show a clear net benefit of extended duration thromboprophylaxis when compared to standard (7-10 days) prophylaxis with LMWH (Table 3). ${ }^{27-29}$ Reasons for the lack of net benefit in these trials include the following: inclusion of a population that was not at high enough risk of VTE (control VTE risk $<5 \%$ ) and an excess in bleeding (2.5 times control rate) offsetting the modest efficacy benefit (Table 3). Patient selection on the basis of VTE and bleeding risk is therefore a key determinant of trial success.

To address the challenges of extended VTE prophylaxis in medical patients, the APEX study uses an enrichment design, in which patients at high risk of VTE are selected based on patient/disease-related factors and/or the results of D-dimer performed at baseline. ${ }^{14,30}$ As well as informing on the efficacy and safety of extended duration of VTE prophylaxis with betrixaban, the study will inform on the clinical utility of the risk stratification methods used. ${ }^{30}$ By selecting patients on the basis of clinical features and a biomarker, it is hypothesized that a higher VTE risk population will be enrolled (estimated VTE risk in control arm at least 7.5\% at day 35) when compared to previous studies. ${ }^{14}$ Similarly, by using stringent exclusion criteria, it is hypothesized that a population at lower risk of bleeding will be selected. While there is evidence supporting the clinical validity of risk stratification of patients on the basis of clinical features and D-dimer, ${ }^{31-35}$ there is presently no validated bleeding risk stratification tool for medical patients. Moreover, if the same clinical features or laboratory markers that identify patients with high VTE risk predict increased bleeding risk, the putative benefit of the risk stratification strategy may be diminished.

\section{Potential role of betrixaban in VTE prevention and treatment}

The results of the APEX study will be critical to the future prospects of betrixaban. First, if the trial shows that extended duration betrixaban is more effective than 6-14 days of enoxaparin with no appreciable increase in bleeding, betrixaban could be the first NOAC approved for extended thromboprophylaxis in medical patients. In addition, such evidence may launch future clinical development in other thromboprophylaxis indications and in VTE treatment. Second, a favorable efficacy and safety in patients with severe renal impairment would act as a proof of concept and support further evaluation of betrixaban in this population with limited anticoagulant options.

As exemplified by previous trials of the approved NOACs, confirmation of the clinical efficacy and safety of the selected dose in VTE prevention is often a determinant of success for future studies in VTE treatment and stroke prevention in AF. Because the APEX study is comparing the strategy of extended thromboprophylaxis with standard thromboprophylaxis with a single outcome assessment at days 35-42, it does not directly inform on the relative clinical efficacy

Table 3 RCTs evaluating extended thromboprophylaxis in acutely ill medical patient

\begin{tabular}{|c|c|c|c|c|c|c|}
\hline $\begin{array}{l}\text { Study (no of } \\
\text { patient) }\end{array}$ & Population & Intervention & Control & $\begin{array}{l}\text { All VTE rate } \\
\text { (intervention vs } \\
\text { control) }\end{array}$ & $\begin{array}{l}\text { Major bleeding rate } \\
\text { (intervention vs } \\
\text { control) }\end{array}$ & Comments \\
\hline $\begin{array}{l}\text { EXCLAIM }^{27} \\
(n=5,963)\end{array}$ & $\begin{array}{l}\text { Acutely ill medical } \\
\text { patient }\end{array}$ & $\begin{array}{l}\text { Extended duration } \\
\text { enoxaparin }\end{array}$ & Enoxaparin & $2.5 \%$ vs $4.0 \%$ & $0.8 \%$ vs $0.3 \%$ & No net benefit \\
\hline $\begin{array}{l}\text { ADOPT }^{28} \\
(n=6,528)\end{array}$ & $\begin{array}{l}\text { Acutely ill medical } \\
\text { patient }\end{array}$ & $\begin{array}{l}\text { Extended duration } \\
\text { apixaban }\end{array}$ & Enoxaparin & $2.7 \%$ vs $3.1 \%$ & $0.5 \%$ vs $0.2 \%$ & No net benefit \\
\hline $\begin{array}{l}\text { MAGELLAN }{ }^{29} \\
(\mathrm{n}=8,101)\end{array}$ & $\begin{array}{l}\text { Acutely ill medical } \\
\text { patient }\end{array}$ & $\begin{array}{l}\text { Extended duration } \\
\text { rivaroxaban }\end{array}$ & Enoxaparin & $4.4 \%$ vs $5.7 \%$ & I.I\% vs $0.4 \%$ & No net benefit \\
\hline $\begin{array}{l}\operatorname{APEX}^{14}(n=6,850) \\
\text { ongoing }\end{array}$ & $\begin{array}{l}\text { Acutely ill medical } \\
\text { patient }\end{array}$ & $\begin{array}{l}\text { Extended duration } \\
\text { betrixaban }\end{array}$ & Enoxaparin & Awaited & Awaited & $\begin{array}{l}\text { Enrichment design. } \\
\text { Enrolling only patients } \\
\text { at high VTE risk. } \\
\text { Expected all VTE rate } \\
\text { in control arm }=7.5 \%\end{array}$ \\
\hline
\end{tabular}

Abbreviations: VTE, venous thromboembolism; RCTs, randomized controlled trials. 
and safety of the selected dose of betrixaban in comparison to enoxaparin. Before proceeding to Phase III VTE treatment studies, it would be prudent to perform dose finding study in VTE treatment to select optimal treatment dose.

The lack of antidote remains a concern for the NOACs because it complicates the management of patients who experience life-threatening bleeding or who require emergency surgery. Because of its long half-life, betrixaban is particularly vulnerable to this concern. Successful codevelopment of Portola's antidote - Andexanet alfa, an inactive recombinant $\mathrm{FXa}$ - will help allay this concern by providing a ready means to reverse the anticoagulant effect of betrixaban. ${ }^{36-42}$

\section{Conclusion}

Betrixaban is a new FXa inhibitor with unique pharmacokinetic characteristics: minimal renal clearance, minimal hepatic metabolism, and a long half-life. Minimal renal clearance is the most pertinent attribute, which may offer a competitive edge over the approved NOACs, particularly if betrixaban shows favorable efficacy and safety profile in patients with severe renal failure, a population with unmet need. Extended medical thromboprophylaxis is an indication with no competition from other NOACs, but it is also a challenging indication for which a net clinical benefit has remained elusive. The design of the APEX study reflects lessons learnt from previous RCTs with the NOACs and has benefited from recent validation of clinical risk assessment models and laboratory markers such as D-dimer. ${ }^{14}$ Success in the APEX study is critical for the future clinical development of betrixaban.

\section{Disclosure}

JWE reports grant support and honoraria from Astra Zeneca, Bayer, Boehringer Ingelheim, Bristol-Myers-Squibb/Pfizer, Daiichi Sankyo, Glaxo Smith Kline, Janssen, and SanofiAventis and grant support from Eli Lilly. NCC reports travel grant support from Sanofi-Aventis. The other author reports no conflicts of interest in this work.

\section{References}

1. Rathbun S. The surgeon general's call to action to prevent deep vein thrombosis and pulmonary embolism. Circulation. 2009;119(15):e480-e482.

2. Office of the Surgeon General (US), National Heart Lung, and Blood Institute (US). The Surgeon General's Call to Action to Prevent Deep Vein Thrombosis and Pulmonary Embolism. Rockville (MD): Office of the Surgeon General (US); 2008. Available from: http://www.ncbi.nlm. nih.gov/books/NBK44178/. Accessed April 8, 2015.

3. Holbrook A, Schulman S, Witt DM, et al. Evidence-based management of anticoagulant therapy: antithrombotic therapy and prevention of thrombosis, 9th ed: American College of Chest Physicians Evidence-Based Clinical Practice Guidelines. Chest. 2012;141(2_Suppl):e152S-e84S.

4. Bauer KA. Pros and cons of new oral anticoagulants. Hematology Am Soc Hematol Educ Program. 2013;2013:464-470.
5. Yeh CH, Gross PL, Weitz JI. Evolving use of new oral anticoagulants for treatment of venous thromboembolism. Blood. 2014;124(7): $1020-1028$.

6. Schulman S, Kearon C, Kakkar AK, et al. Dabigatran versus warfarin in the treatment of acute venous thromboembolism. N Engl J Med. 2009; 361(24):2342-2352.

7. Schulman S, Kakkar AK, Goldhaber SZ, et al. Treatment of acute venous thromboembolism with dabigatran or warfarin and pooled analysis. Circulation. 2014;129(7):764-772.

8. Bauersachs R, Berkowitz SD, Brenner B, et al. Oral rivaroxaban for symptomatic venous thromboembolism. N Engl J Med. 2010;363(26): 2499-2510.

9. Buller HR, Prins $\mathrm{MH}$, Lensin AW, et al. Oral rivaroxaban for the treatment of symptomatic pulmonary embolism. N Engl J Med. 2012; 366(14):1287-1297.

10. Agnelli G, Buller HR, Cohen A, et al. Oral apixaban for the treatment of acute venous thromboembolism. N Engl J Med. 2013;369(9):799-808.

11. Buller HR, Decousus H, Grosso MA, et al. Edoxaban versus warfarin for the treatment of symptomatic venous thromboembolism. $N$ Engl $J$ Med. 2013;369(15):1406-1415.

12. Connolly SJ, Eikelboom J, Dorian P, et al. Betrixaban compared with warfarin in patients with atrial fibrillation: results of a phase 2, randomized, dose-ranging study (Explore-Xa). Eur Heart J. 2013;34(20): $1498-1505$.

13. Turpie AG, Bauer KA, Davidson BL, et al. A randomized evaluation of betrixaban, an oral factor Xa inhibitor, for prevention of thromboembolic events after total knee replacement (EXPERT). Thromb Haemost. 2009;101(1):68-76.

14. Cohen AT, Harrington R, Goldhaber SZ, et al. The design and rationale for the Acute Medically Ill Venous Thromboembolism Prevention with Extended Duration Betrixaban (APEX) Study. Am Heart J. 2014;167(3):335-341.

15. Zhang P, Huang W, Wang L, et al. Discovery of betrixaban (PRT054021), $\mathrm{N}$-(5-chloropyridin-2-yl)-2-(4-(N,N-dimethylcarbamimidoyl) benzamido)-5-methoxybenz amide, a highly potent, selective, and orally efficacious factor Xa inhibitor. Bioorg Med Chem Lett. 2009;19(8): 2179-2185.

16. Sinha U, Edwards ST, Wong PW, et al. Antithrombotic activity of PRT54021, a potent oral direct factor Xa inhibitor, can be monitored using a novel prothrombinase inhibition bioassay. Blood. 2006;108(11): 272A-A.

17. Abe K, Siu G, Edwards S, et al. Animal models of thrombosis help predict the human therapeutic concentration of PRT54021, a potent oral factor Xa inhibitor. Blood. 2006;108(11):270A-A.

18. ClinicalTrials.gov. NCT01765868: A Human Phase I Absolute Bioavailability Study of PRT054021 in Healthy Male Volunteers 2012; 2015 [cited July 31, 2013]. Available from: http://clinicaltrial.gov/ct2/ show/NCT01765868?term=betrixaban\&rank $=5$. Accessed 8 April, 2015 .

19. ClinicalTrials.gov. NCT01765855: An Open-Label, Single-Dose, MassBalance Study to Assess the Disposition of 14C-Labeled PRT054021 in Healthy Male Subjects; 2015. Available from: http://clinicaltrial.gov/ ct2/show/NCT01765855?term=betrixaban\&rank $=6$. Accessed April 8, 2015.

20. Hutchaleelaha A, Ye C, Song Y, Lorenz T, Gretler D, Lambing JL. Metabolism and disposition of betrixaban and its lack of interaction with major CYP enzymes. ASH Annu Meet Abstr. 2012;120(21):2266.

21. Bathala MS, Masumoto H, Oguma T, He L, Lowrie C, Mendell J. Pharmacokinetics, biotransformation, and mass balance of edoxaban, a selective, direct factor Xa inhibitor, in humans. Drug Metab Dispos. 2012;40(12):2250-2255.

22. Blech S, Ebner T, Ludwig-Schwellinger E, Stangier J, Roth W. The metabolism and disposition of the oral direct thrombin inhibitor, dabigatran, in humans. Drug Metab Dispos. 2008;36(2):386-399.

23. Weinz C, Schwarz T, Kubitza D, Mueck W, Lang D. Metabolism and excretion of rivaroxaban, an oral, direct factor Xa inhibitor, in rats, dogs, and humans. Drug Metab Dispos. 2009;37(5):1056-1064. 
24. Zhang D, He K, Raghavan N, et al. Comparative metabolism of 14Clabeled apixaban in mice, rats, rabbits, dogs, and humans. Drug Metab Dispos. 2009;37(8):1738-1748.

25. Morganroth J, Gretler DD, Hollenbach SJ, Lambing JL, Sinha U. Absence of QTc prolongation with betrixaban: a randomized, double-blind, placebo- and positive-controlled thorough ECG study. Expert Opin Pharmacother. 2013;14(1):5-13.

26. ClinicalTrials.gov. NCT01583218: Acute Medically Ill VTE Prevention With Extended Duration Betrixaban Study (The APEX Study); 2015. Available from: http:/clinicaltrial.gov/ct2/show/NCT01583218?term= betrixaban\&rank=3. Accessed April 8, 2015.

27. Hull RD, Schellong SM, Tapson VF, et al. Extended-duration venous thromboembolism prophylaxis in acutely ill medical patients with recently reduced mobility: a randomized trial. Ann Intern Med. 2010;153(1):8-18.

28. Goldhaber SZ, Leizorovicz A, Kakkar AK, et al. Apixaban versus enoxaparin for thromboprophylaxis in medically ill patients. $N$ Engl J Med. 2011;365(23):2167-2177.

29. Cohen AT, Spiro TE, Buller HR, et al. Rivaroxaban for thromboprophylaxis in acutely ill medical patients. N Engl J Med. 2013;368(6):513-523.

30. Cohen AT, Harrington R, Goldhaber SZ, et al. Recognition of biomarker identified high-risk patients in the acute medically ill venous thromboembolism prevention with extended duration betrixaban study resulting in a protocol amendment. Am Heart J. 2015;169(1):186-187.

31. Barbar S, Noventa F, Rossetto V, et al. A risk assessment model for the identification of hospitalized medical patients at risk for venous thromboembolism: the Padua prediction score. J Thromb Haemost. 2010;8(11):2450-2457.

32. Spyropoulos AC, Anderson FA Jr, Fitzgerald G, et al. Predictive and associative models to identify hospitalized medical patients at risk for VTE. Chest. 2011;140(3):706-714.

33. Woller SC, Stevens SM, Jones JP, et al. Derivation and validation of a simple model to identify venous thromboembolism risk in medical patients. Am J Med. 2011;124(10):947-954. e2.

34. Rosenberg D, Eichorn A, Alarcon M, McCullagh L, McGinn T, Spyropoulos AC. External validation of the risk assessment model of the International Medical Prevention Registry on Venous Thromboembolism (IMPROVE) for medical patients in a tertiary health system. $J$ Am Heart Assoc. 2014;3(6):e001152.
35. Cohen AT, Spiro TE, Spyropoulos AC, et al. D-dimer as a predictor of venous thromboembolism in acutely ill, hospitalized patients: a subanalysis of the randomized controlled MAGELLAN trial. JThromb Haemost. 2014;12(4):479-487.

36. Lu G, DeGuzman FR, Hollenbach SJ, et al. A specific antidote for reversal of anticoagulation by direct and indirect inhibitors of coagulation factor Xa. Nat Med. 2013;19:446-451.

37. Crowther MA, Kitt M, McClure M, et al. Randomized, doubleblind, placebo-controlled single ascending dose pharmacokinetic and pharmacodynamic study of PRT064445, a universal antidote for factor Xa inhibitors (abstract). Arterioscler Thromb Vasc Biol. 2013;33:A10.

38. Crowther MA, Mathur V, Kitt M, et al. A phase 2 randomized, double-blind, placebo-controlled trial demonstrating reversal of rivaroxaban-induced anticoagulation in healthy subjects by andexanet alfa (PRT064445), an antidote for FXa inhibitors (abstract). Blood. 2013;122:A3636.

39. Crowther MA, Kitt M, Lorenz T, et al. A phase 2 randomized, doubleblind, placebo-controlled trial of PRT4445, a novel, universal antidote for direct and indirect Factor Xa inhibitors (abstract). JThromb Haemost. 2013;11:AS20.1.

40. Crowther M, Levy G, Lu G, et al. ANNEXA ${ }^{\mathrm{TM}}$ A: a Phase 3 randomized, double-blind, placebo-controlled trial, demonstrating reversal of apixaban-induced anticoagulation in older subjects by Andexanet alfa (PRT064445), a universal antidote for factor Xa (fXa) inhibitors (abstract). Circulation. 2014;130:2105-2126.

41. Hollenbach S, Tan S, DeGuzman F, et al. PRT064445 reverses rivaroxaban induced antiacogulation in a rabbit liver laceration treatment model (abstract). Eur Heart J. 2013;34:24.

42. Hollenbach S, Lu G, DeGuzman F, et al. Abstract 14657: andexanetalfa and PER977 (Arapazine) correct blood loss in a rabbit liver laceration model - only andexanet reverses markers of fXa-mediated anticoagulation. Circulation. 2014;130(Suppl 2):A14657.
Vascular Health and Risk Management

\section{Publish your work in this journal}

Vascular Health and Risk Management is an international, peerreviewed journal of therapeutics and risk management, focusing on concise rapid reporting of clinical studies on the processes involved in the maintenance of vascular health; the monitoring, prevention and treatment of vascular disease and its sequelae; and the involvement of

\section{Dovepress}

metabolic disorders, particularly diabetes. This journal is indexed on PubMed Central and MedLine. The manuscript management system is completely online and includes a very quick and fair peer-review system, which is all easy to use. Visit http://www.dovepress.com/ testimonials.php to read real quotes from published authors. 